\title{
Manipulação midiática ou a dimensão declaratória da memória? ${ }^{1}$
} Marialva Carlos Barbosa

\section{Resumo}

A partir de um exemplo histórico da política do século XX - a crise do Segundo Governo Vargas - o objetivo do texto é mostrar como, na dimensão memorável, os meios de comunicação fazem uso de articulações discursivas em torno de um mesmo acontecimento, produzindo uma narrativa em que o esquecimento assume papel central. Sobressai na análise do período que antecede 0 (quase) desfecho da crise de 1954 - que culmina com o suicídio de Vargas - a dimensão profunda de uma memória jornalística que se atualiza sem cessar.

\section{Palavras-Chave}

Memória. Meios de Comunicação. Governo Vargas.
Marialva Carlos Barbosa I marialva153@gmail.com Professor titular da Escola de Comunicação da Universidade Federal do Rio de Janeiro - UFRJ, Brasil. Professor do Programa de Pós-Graduação em Comunicação e Cultura da UFRJ. Pesquisador 1 do CNPq.

\section{Introdução}

0 exercício reflexivo que propomos nesse texto, a partir da análise das notícias da crise de 1954 no jornal 0 Globo, e que culmina com o que está sendo denominado reconfiguração memorável, engendrada por articulações discursivas dos meios de comunicação, tem por objetivo mostrar como nessa memória produzida e fixada há peculiaridades que devem ser consideradas.

Trazendo do passado para o presente argumentos, palavras de ordem, expressões, atores políticos em ação, há uma certa recorrência dos contextos e das articulações narrativas que desaguam na produção jornalística. Esses cenários e as configurações narrativas do jornalismo reaparecem historicamente, produzindo uma espécie de reatualização memorável que faz emergir as mesmas palavras, os mesmos argumentos, os mesmos fatos como definidores de momentos de incerteza.

Esse movimento induz a pensar nas permanências memoráveis e numa memória parcialmente 
adormecida que emerge periodicamente nos meios de comunicação, obrigando-nos a refletir sobre uma memória anteriormente domesticada e submersa que aflora com contundência em momentos de crise. Transforma-se, assim, em memória declaratória que, retirada dos mecanismos encobridores, assume discursivamente os parâmetros que qualificam e apresentam de fatos, produzindo uma linha de continuidade em relação ao passado.

Refletindo detidamente sobre os fatos apresentados, os argumentos utilizados, as imagens sacralizadas para imputar culpa ao presidente Getúlio Vargas pelo ato que selaria a crise política vivenciada no país - o crime da Toneleros que vitimou o jornalista e político Carlos Lacerda e matou o major da Aeronáutica Rubem Vaz, ocorrido em 5 de agosto de 1954 observamos não um apagamento da memória (TODOROV, 1995), mas a emergência da construção jornalística a serviço de uma memória duradoura e que seria acionada em outros momentos históricos.

Analisando as primeiras páginas de $O$ Globo de 5 de agosto de 1954 até 24 de agosto daquele ano, quando o suicídio de Vargas suspendeu temporariamente a produção narrativa dominante nos jornais que formaram um bloco de poder em torno da deposição de Vargas, observamos o destaque que 0 jornal deu, naquele momento de crise, ao que qualificava como a corrupção que tomava conta do Governo Vargas e era imputada também ao presidente. Há, ao nosso vez, uma permanência memorável que relaciona a campanha de 1954 à emergência dos mesmos argumentos usados, por exemplo, na campanha midiática de 2017 tendo como central os processos da chamada Operação Lava Jato.

A semelhança das práticas editorais adotadas pelo jornal, 63 anos depois, na crise política contemporânea, decorre, a nosso ver, não apenas da existência de fatos políticos análogos, mas também da adoção dos mesmos processos jornalísticos que, assim, são submetidos a articulações narrativas dependentes da construção memorável que coloca em cena a literalidade ou a exemplaridade memorável (TODOROV, 1995, p. 32-33).

Não se trata, portanto, apenas de um abuso da memória (TODOROV, 1995), mas da reatualização de algo que ficou escondido durante décadas e que, reconstruído em outro tempo, produz uma declaração jornalística análoga, de tal forma que podemos nos referir a uma memória declaratória da mídia. Essa se configura quando a partir dos mecanismos de construção do acontecimento e através da produção discursiva engendra uma linha de continuidade do presente com 0 
passado, que, mesmo não mencionado, aparece memorialísticamente na cena construída.

\section{A cobertura do fato Toneleros e os argumentos de 0 Globo}

Mas o Presidente constitucional desde logo se colocou numa posição sectária, criando e animando a luta de classes, esforçando-se por implantar o predomínio do seu partido, que nunca dispôs senão de uma sexta parte do número total de deputados, recorrendo a escoIhas de homens suspeitos para 0 exercício de certos postos-chaves da administração e da política, tentando infiltrar-se nos partidos de opinião por processos de condenável aliciamento. Em breve, a corrupção espraiou-se no Governo e os dinheiros públicos foram tratados como patrimônio privado; a demagogia assumiu tal preponderância nas decisões oficiais que, por vezes, ouvindo-se as falas presidenciais, se tinha a impressão que 0 chefe do Governo era o chefe da oposição! Tudo isso para, pouco a pouco, ir sendo criado um clima antidemocrático capaz de conduzir a todas as loucuras e a todas as negações e subversões da Constituição. (0 Globo, 10 de agosto de 1954, p. 1).

Se não fosse a data de publicação do editorial

"Contra o Crime, mas sempre pela Constituição e a Democracia”, poderíamos confundir o tempo de sua veiculação pelo jornal carioca. Esse poderia ter sido um texto escrito em 2017.

Os argumentos usados enumeram as mesmas cadências factuais que pelos mecanismos de memória comparecem nas páginas de $O$ Globo para justificar a tomada de posição e de partido, para se insurgir contra um governo constitucionalmente eleito e contra um presidente que tinha 0 aval e 0 apoio da maioria da população.

Os discursos de que 0 "Presidente se colocou numa posição sectária, criando e animando a luta de classes", de que não media esforços para "implantar o predomínio de seu partido", tendo para isso "recorrido a escolhas de homens suspeitos para 0 exercício de certos postoschaves da administração e da política, tentando infiltrar-se nos partidos de oposição por processos de condenável aliciamento" são periodicamente reapropriados pelo jornal, quando o objetivo é 0 desmonte e a cassada implacável a uma figura pública. Foi assim na campanha contra Jango, em 1964, tem sido assim também na campanha contra o ex-presidente Lula em 2016/2017.

\section{A corrupção aparece, então, como uma} senha constantemente atualizada, ao lado da qualificação, como demagógica, da forma como o presidente Vargas se dirigia à população.

0 apelo final faz emergir a oposição que os meios de comunicação de forma hegemônica exerceram contra 0 Presidente e 0 argumento usado pelo jornal $O$ Globo (bem como pelos outros periódicos que se engajaram na campanha liderada pela Tribuna da Imprensa de Carlos Lacerda) em fazer valer os preceitos constitucionais.

0 argumento da corrupção também é repetido inúmeras vezes. Um exemplo é o trecho do editorial em que 0 jornal relaciona a perda da 
confiança dos dirigentes à corrupção que teria recebido o "bafejo oficial".

É o que sucede sempre quando a Nação perde a confiança nos seus dirigentes, quando os métodos do Governo se inspiram na duplicidade; sobretudo quando a corrupção recebe 0 bafejo oficial (...). Mas desgraçadamente 0 atual Governo foi lentamente, decepcionando mesmo os seus amigos mais sinceros, por atos e omissões que hoje constituem o caldo negativo de quatro exercícios de um poder por vezes inerte, contraditório nas suas diretrizes, preocupado quase só de fazer política com os homens e as ambições dos partidos sem jamais escolher uma diretriz forte e constante num plano de realizações ou abandonando inexplicavelmente certos bons rumos que de começo traçara. (0 Globo, 10 de agosto de 1954, p. 1).

Como palavra de ordem, ao final, $O$ Globo

relembra o lugar de fala que ocupa na sociedade, reconhecendo-se como porta-voz da "opinião conservadora do país", daqueles que desejam que "o progresso se faça pela evolução natural, não pelos abalos revolucionários".

Afinal, um governo que se caracterizava e traçava ações para atender 0 anseio da maioria e, assim, aproximava-se, na argumentação do texto, de grupos esquerdistas (ou tidos como tal), não interessava mais ao jornal que no passado - como no presente - advogava em favor das forças conservadoras. Como porta-voz das elites conservadoras, 0 jornal orgulha-se de ter sua história - e para isso aciona novamente laços daquele presente com o passado atrelada a este papel.
Este jornal, em sua já longa carreira, sempre se conservou fiel às razões que inspiraram Irineu Marinho no ato de sua fundação. Somos e gostamos de ser um órgão de opinião conservadora do país; um reflexo das tendências médias de nossos concidadãos, dos anseios e esperanças de quantos desejam que o progresso se faça pela evolução natural, não pelos abalos revolucionários. Em suja, desejamos falar sempre por aquela imensa maioria dos brasileiros que o Sr. João Goulart, em seu arrivismo oratório, denomina "os reacionários". Daí, a nossa autoridade para concitarmos o Governo e o Povo a se conterem dentro das regras constitucionais, punindo-se os autores do crime, sem contemplação, mas preservando-se a firme democracia e realizando-se a 3 de outubro as eleições marcadas. (0 Globo, 10 de agosto de 1954, p. 1)

Como porta-voz dos "reacionários", o jornal acreditava ter autoridade suficiente para lutar pela ordem constitucional. E isso significava "punir os autores do crime", incluindo evidentemente o Presidente que, sub-repticiamente, aparecia como possível mandante do crime da Toneleros. Na sequência, o jornal advoga sua substituição imediata em torno do argumento da manutenção da democracia.

Dois dias depois, em 12 de agosto de 1954, 0 jornal, logo após a manchete que dizia "Não foi discutida a renúncia do Presidente da República na reunião das classes armadas", publica outro editorial sob o título "Feixe das Varas e a União das Classes Armadas".

Depois de falar do "choque emocional que a tragédia da Rua Toneleros provocou em todas as 
classes sociais", dizia que não havia dúvidas do plano para eliminar Carlos Lacerda e que mesmo não sendo necessário atribuir ao Sr. Getúlio Vargas ou a seu filho mais velho Luthero Vargas a "ordem de fuzilar traiçoeiramente 0 jornalista", a responsabilidade era do Governo. E exortava:

\footnotetext{
Mantenham-se os homens de farda unidos e fiéis à Pátria, acima de políticos ou partidos, e a crise será superada sem prejuízo - antes com vantagem - para a punição dos criminosos por mais poderosos que sejam ("Feixe das Varas e a União das Classes Armadas". In: 0 Globo, 12 de agosto de 1954, p. 1).
}

Na sequência, o jornal oferecia uma solução pacífica: conclamar a união em torno de Eduardo Gomes, candidato conservador que iria disputar as eleições de outubro. A crise servia, então, nos argumentos de $O$ Globo, para dar um novo rumo - 0 desejado pelas elites conservadoras - ao país sob o manto do candidato do bloco de poder da mídia.

\begin{abstract}
A figura do brigadeiro Eduardo Gomes mais uma vez se afirmou na condição popular, pela sua nobreza, energia serena e espírito cívico. Os anos não arrefeceram o herói de Copacabana, a chama que lançou na praia os jovens tenentes de 1922. 0 feixe de varas é ainda um símbolo para a redenção do Brasil nesses dias difíceis ("Feixe das Varas e a União das Classes Armadas". In: 0 Globo, 12 de agosto de 1954, p. 1).
\end{abstract}

Se em 1954, o mito que desejavam construir do salvador era capitaneado na figura de Eduardo Gomes - 0 herói combatente de Copacabana (da Revolta Tenentista de 1922) e que poderia também combater pelo Brasil - em 2017, o herói que encabeça a cruzada antigoverno, sobretudo os governos passados que se aproximavam de ações tidas como incomuns (ou "revolucionárias"), advém não mais das Forças Armadas, mas do Judiciário. 0 herói salvador é sempre um argumento forte para a construção artificial de líderes que não se sustentam por muito tempo.

Assim, ao visualizarmos a campanha da imprensa, como um bloco de poder (GRAMSCI, 1978), no caso aqui representada pelo jornal 0 Globo, mas cuja argumentação, com maior ou menor divergência se aproximava em todos os jornais do período, com exceção de Ultima Hora, não podemos atribuir as suas construções discursivas e a campanha pela deposição do Presidente a uma razão de manipulação midiática. Seria muito simplista e, sobretudo, uma visão da mídia como detentora de um poder monolítico.

Se considerarmos, tal como Rousso (2016, p. 34), que os discursos se constituem sempre em torno de uma oposição dual entre presente e passado, entre a exigência de uma verdade e 0 tabu imposto desde 0 passado, há sempre a necessidade de proclamar a tomada da palavra, mesmo que tardia, em contraposição ao silêncio que existia outrora. Trata-se da dualidade conflituosa entre memória e esquecimento, "como uma luta, entre luz e obscuridade" (ROUSSO, 2016, p. 34).

A luz lançada discursivamente pelo jornal $O$ Globo, na dura campanha que empreendeu contra Getúlio Vargas, em 1954, era decorrente do desvendamento da trama que o próprio jornal 
ajudara a construir. Revelar os fatos obscuros que envelopavam, na opinião do jornal, o crime da Toneleros, era trazer para a lembrança os preceitos políticos desejados pelo jornal e pelos grupos que representavam. Assim, toma da palavra e, para isso, constrói sua argumentação, produzindo várias continuidades históricas reveladas a partir de trabalhos de memória: a construção artificial do mito Eduardo Gomes como combatente; a reafirmação do papel do jornal como representante dos grupos conservadores; e a obrigatoriedade de desvelar os acontecimentos presentes para preservar o futuro do país.

Traça-se, assim, uma relação entre passado, presente e futuro, determinante para fazer avançar a história em novas bases. Se os mecanismos da memória são acionados para mostrar o papel do jornal na luta pela democracia brasileira, o futuro é evocado como possibilidade redentora, caso no presente se realizassem as ações desejadas. E essas se nutriam da demolição da figura pública de Vargas, relacionando-o a personagens tidos como corruptos e que eram encobertados pelo Presidente.

\section{$\mathbf{O}$ desfecho da trama}

Até aqui nos referimos aos modos narrativos de uma memória declaratória produzida pelo jornalismo que aciona, periodicamente, os mesmos contextos para construir um quadro de crise política, em nome da instabilidade dos rumos do país. Apresentamos, agora, outras imagens que compõem a primeira página do jornal para mostrar como se dá a articulação entre lembrança e esquecimento na produção memorável. Uma produção memorável baseada numa seleção que coloca em evidência determinados traços e oculta outros, elevando-os à condição de algo ausente.

A falta, como remarca Henri Rousso (2016, p. 42), pode significar algo além do esquecimento propriamente dito. Não estar presente na narrativa memorável pode supor também o silêncio, a ocultação, a amnésia, a negação, a supressão, numa "lista exaustiva de registros muito diferentes uns dos outros e, portanto, utilizados de maneira indiferenciada". "Esquecer pode ser se calar, negar ou suprimir, o que não é a mesma coisa", acrescenta Rousso (2016, p. 42).

Comparando as edições de agosto de 1954 de $O$ Globo e do jornal Ultima Hora, aliado incondicional de Vargas, sobressai a dimensão de esquecimento produzida pela escolha de fatos em o Globo, que sequer figuram como possibilidade narrativa no jornal de Samuel Wainer. No caso de Última Hora, a ênfase recai nas declarações presidenciais, enquanto o jornal de Roberto Marinho vai construindo uma espécie de seriado em capítulos sobre a caçada aos pistoleiros que ora teriam sido contratados por Luthero Vargas (filho do Presidente), ora por Gregório Fortunato, chefe da Guarda pessoal de Getúlio.

Assim, no dia 11 de agosto, enquanto a manchete de $O$ Globo gritava "Prisão do homem-chefe a 
qualquer instante!", o jornal de Samuel Wainer destacava como texto principal da sua primeira página a "Tabela oficial para 0 aumento dos servidores", ocupando todo o terço superior do jornal. A notícia sobre o caso da Toneleros vinha estampada no terço inferior da página com 0 seguinte título: "Pistoleiro em Caxias, chantagista no Rio e assassino em Minas!" (O Globo 11 de agosto de 1954 e Ultima Hora, 11 de agosto de 1954, p. 1). A ênfase mais uma vez recai sobre os esforços empreendidos pelo Governo para a punição dos culpados.

Dois dias depois, $O$ Globo destacava: "Preparada mesmo a fuga dos pistoleiros pelo subchefe da guarda presidencial". E complementavam a manchete, com uma foto de Getúlio ao lado do presidente do Supremo Tribunal Federal, José Linhares, em que o subchefe José Antônio Almeida aparece entre ambos. Na mesma página, uma matéria secundária anuncia: "A confissão implícita de Gregório Fortunato".

Já em Última Hora, a fala do Presidente assumia a dimensão de construção de um futuro possível baseado no presente: "Não permitirei que agentes da mentira levem o país ao caos", era a advertência de Vargas, segundo o jornal, aos "fomentadores da provação e da desordem". E a chamada antecipava algumas das falas do Presidente:

Em sensacional entrevista, o Chefe da Nação exclama: "Enquanto eu planto usinas para a emancipação econômica do país, meus adversários tentam plantar a desordem nas ruas para escravizar o povo aos seus interesses escusos" - "Sou presidente eleito e pretendo desempenhar meu mandato até o fim. Nem um minuto mais" - "Jamais pensei em renunciar". (Ultima Hora, 13 de agosto de 1954, p. 1)

No dia 14 de agosto, um novo ingrediente é acrescentado à trama construída pelo 0 Globo $\mathrm{e}$ que preparava o desfecho desejado para a crise: a renúncia do Presidente. "0 autor do atentado já foi preso e confessou. Teria afirmado que agira a mando do senhor Luthero Vargas, não para eliminar Carlos Lacerda, mas apenas para atingilo no pé" (O Globo, 14 de agosto de 1954, p. 1).

Numa estratégia antecipatória, Última Hora informa "Lutero Vargas renuncia às imunidades para que surja toda a verdade!" e como subtítulo dava voz ao filho do Presidente: "Juro, perante Deus e a Nação, que nenhuma responsabilidade tive nos acontecimentos!" (Ultima Hora, 14 de agosto de 1954, p. 1). Promovia, assim, a condição de esquecimento a confissão do possível autor do atentado e reforçava a disposição do Governo de não medir esforços para apurar 0 crime.

Enquanto o jornal de Roberto Marinho continuava com sua narrativa em capítulos exortando para se desvendasse 0 nome do verdadeiro mandante do crime (atribuído, mesmo sem a fala explícita, ao Presidente da República), Última Hora procurava mostrar que estava em curso um golpe de estado para depor o presidente constitucionalmente eleito: "Pela paz, contra a calúnia e o golpe", destacava no mesmo dia a propósito das 
declarações dos ministros da Guerra da Marinha

e do Comandante da Zona Militar Centro do

Exército (Última Hora, 14 de agosto de 1954, p. 1).

Dois dias depois, em 16 de agosto, 0 Globo

informava que Gregório Fortunato fora preso e recolhido, incomunicável, ao Hospital Central da

Marinha. A manchete do dia em letras garrafais anunciava: "Nas pegadas do chefe dos pistoleiros". No dia seguinte, Climério, um dos autores do atentado, segundo as investigações, era preso:

"Preso Climério", dizia a manchete, para, na sequência, esmiuçarem:

Já está recolhido à Base Aérea do Galeão. Forças de terra e ar na mais sensacional diligencia de todos os tempos - Fugira da casa onde se acoitara à aproximação da caravana que ia capturá-lo - A noite, invadiu uma residência para apoderar-se de roupas - Confirmaram-se todas as revelações da reportagem d'0 GLOBO que, desde sábado, estava nas pegadas do sicário Até o ministro da Guerra no local - Nova busca no Palácio do Catete - Apreendidos milhares de cartas de correspondência particular de Gregório Fortunato - João Valente de Souza levado pelo coronel Adil de Oliveira à residência presidencial para a apreensão - Já em liberdade a esposa do chefe da guarda - José Antônio Soares, outro pistoleiro quer entregar-se à a prisão (O Globo, 16 de agosto de 1954, p. 1).

No dia 18 de agosto, a manchete do jornal deixava antever nas entrelinhas o possível envolvimento do presidente: "Documentos arrancados de Gregório revelariam 0 verdadeiro mandante!".

Dois dias depois, 0 ingrediente da corrupção volta novamente com força explosiva às matérias do jornal. 0 chefe da Guarda Pessoal de Getúlio, Gregório Fortunato, é acusado de ser intermediário em negociatas, de receber comissões de 52 milhões de cruzeiros, de ter adquirido uma fazenda de um filho de Getúlio Vargas. Além disso, sua esposa era sócia de um "mercadinho de Copacabana". E para culminar suas "despesas pessoais eram elevadas" e ele "teria comprado um cavalo de corridas"

\section{Tenente Gregório intermediário de escusas negociatas na CEXIM. Importações sem cober- tura cambial e comissões de $\mathbf{5 2}$ milhões de cruzeiros - 0 ex-chefe da guarda pessoal do Presidente adquiriu, por cerca de 4 milhões de cruzeiros, uma fazenda a um filho do $\mathrm{Sr}$. Getúlio Vargas - Sócia a esposa de Fortunato do mercadinho de Copacabana - Despesas pessoais elevadas e compra de um cavalo de corridas (O Globo, 20 de agosto de 1954, p. 1).}

No dia 21 de agosto, a afirmação de que "Teria 0 Presidente da República violado o compromisso sagrado de defender as leis". Mais uma vez a acusação de que havia corrupção desenfreada no Governo Vargas. "Nunca se pensou que se roubasse tanto", exclama o Sr. Maurício Joppert $(O$ Globo, 21 de agosto de 1954, p. 1).

Na véspera do suicídio de Vargas, a manchete e a primeira página de $O$ Globo repetiam sem cessar a palavra renúncia: "0 Sr. Café Filho propõe dupla renúncia em benefício da Salvação Nacional". "Recusada a proposta pelo Governo. 0 Presidente da República recusa-se a renunciar". "0

Getúlio só renunciará depois de morto.

Uma frase do Ministro da Guerra a propósito 
da situação". "Não renunciarei. Como o Sr. Getúlio Vargas respondeu à proposta que lhe levou o marechal Mascarenhas" (O Globo, 23 de agosto de 1954, p. 1).

No mesmo dia, a edição de Última Hora traz como manchete "0 Brasil escapa à Guerra Civil". No alto, um box ilustrado com um retrato do presidente Vargas informava: "Tranquilo o Catete" (Última Hora, 23 de agosto de 1954, p.1).

Quais conclusões podemos tirar a respeito de duas abordagens jornalísticas tão diametralmente opostas na véspera do dia do desfecho da trama: 0 suicídio do Presidente?

Trata-se de duas dimensões do esquecimento que se configuram na memória declaratória dos jornais. Enquanto $O$ Globo centra na palavra renúncia, a partir da reiteração da expressão inúmeras vezes, o desfecho que desejava, Última Hora procurava mostrar que os militares apoiavam 0 Governo e que garantiriam a ordem. Última Hora silencia o movimento em torno da pressão exercida por vários grupos pela renúncia do Presidente, adotando a estratégia da supressão da informação, enquanto $O$ Globo nega a tranquilidade presumida no Palácio do Catete. São duas proposições de esquecimento que vemos no trabalho memorável jornalístico: a supressão e a negação.

Observa-se, então, nos dois jornais aquilo que Rousso (2016) qualifica como um déficit de palavra e não de memória. Trata-se dos silêncios produzidos e supostos que, de certa forma, blindam determinadas expressões e, por contraponto, colocam em evidência outros termos que se constituem em sínteses, no caso do evento estudado, históricas das crises políticas no país.

Corrupção e renúncia aparecem como uma espécie de memória declaratória e deliberativa de $O$ Globo que, retornando periodicamente em outras situações e construídas discursivamente pelos meios de comunicação, sintetizam no presente as memórias passadas e traumáticas da política brasileira.

No trágico dia seguinte, 24 de agosto, embora a edição do dia anterior do jornal de Samuel Wainer não tenha feito qualquer menção à declaração de Vargas de que "só renunciaria depois de morto", enfatizada pelo $O$ Globo, a frase premonitória de Getúlio é a manchete de Última Hora: "0 presidente cumpriu a palavra: só morto sairei do Catete!", exclamava 0 periódico de Wainer. 


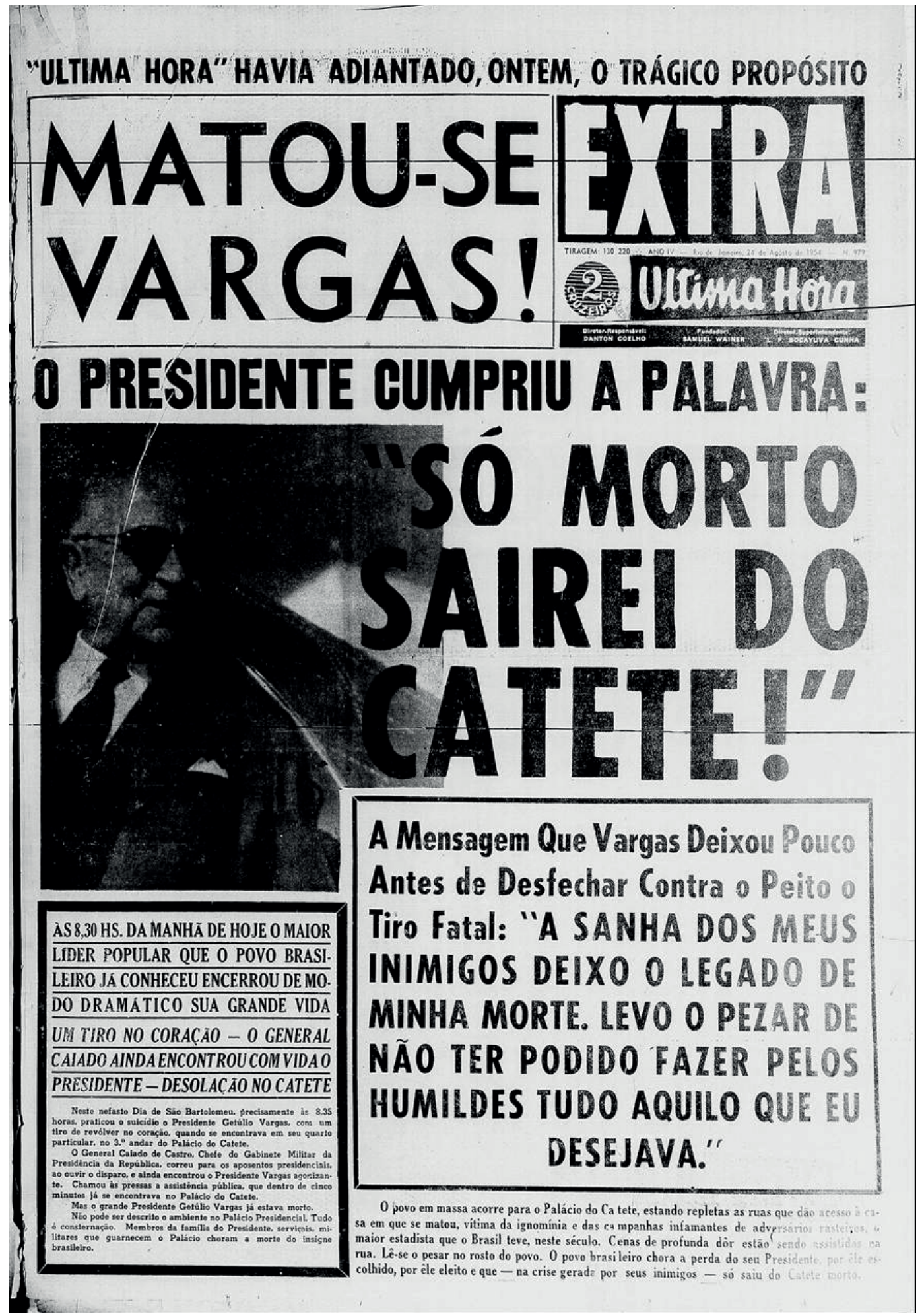

Fonte: Última Hora, 24 de agosto de 1954. Edição Extra (n. 979), p. 1. Hemeroteca Digital da Biblioteca Nacional. 
Nesse processo, recupera, portanto, uma frase dita na véspera e divulgada pela imprensa oposicionista (e que fora elevada à dimensão de silêncio no jornal Última Hora), retirando do esquecimento para a lembrança a declaração de Vargas. Apagando o silêncio momentaneamente construído, produz a edição em torno do tema proposto inicialmente por seus opositores e, com ele, constrói a síntese narrativa da notícia: o cumprimento da palavra do Presidente, isto é, renúncia só com a morte.

Mas outras dimensões do esquecimento foram também acionadas nas edições seguintes, sobretudo, aquelas que tratam da despedida do Presidente diante da multidão enlutada ou aquela que mostra o translado do corpo, pelas ruas da cidade, em direção ao Aeroporto Santos Dumont, aonde seria embarcado para 0 enterro em S. Borja.
A imagem da multidão tomando conta das ruas da cidade se constitui naquilo que Paul Ricouer (2007) classifica como "esquecimento de reserva". São imagens de cortejos que são divulgadas sempre na mesma perspectiva: do alto se vê a multidão tomando conta das ruas, em uma parada cívica, em torno do morto. A mesma imagem se repete nos meios de comunicação, no mesmo ângulo, reproduzindo o mesmo cenário. As imagens de Vargas morto, velado pelo povo, e aclamado nas ruas, são semelhantes às que foram construídas e publicadas quando da morte do ex-presidente Juscelino Kubistchek ou ainda em torno do cortejo de Tancredo Neves. São cenas conceituais que de tanto voltar, de tanto serem acionadas, constituem-se em uma dimensão do esquecimento que é produzido a partir da profusão de lembranças. 
Figura 2: Última Hora e o cortejo de Vargas

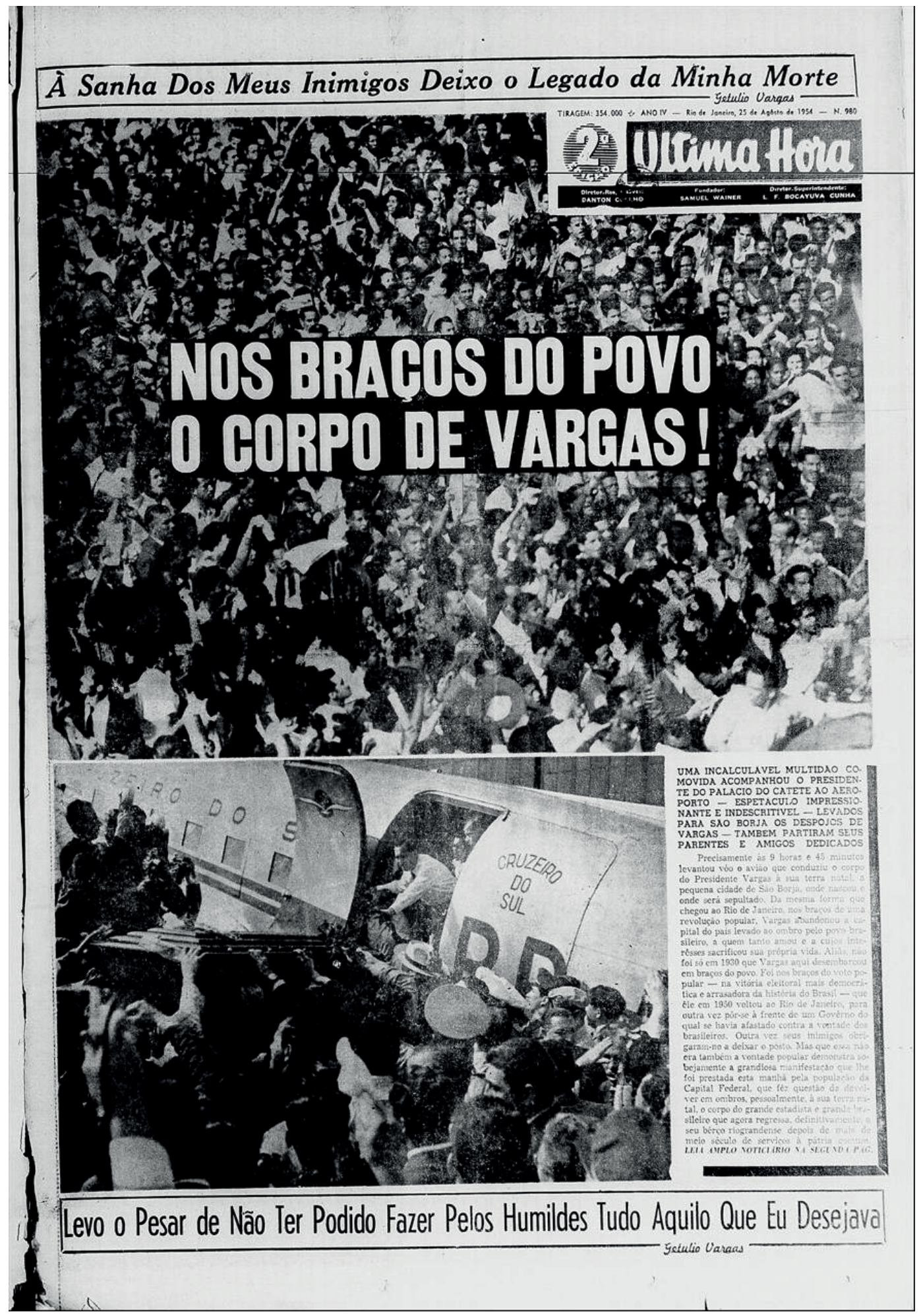

Fonte: Última Hora, 24 de agosto de 1954, 2a. edição (n. 980), p. 1. Hemeroteca Digital da Biblioteca Nacional. 
Passados os primeiros dias de impacto diante do desfecho inesperado da trama e que causou surpresa em todos os setores da vida pública brasileira, o jornal $O$ Globo voltou, já no início de setembro, a carga contra os possíveis mandantes do crime da rua Toneleros. Em 6 de setembro, a manchete revelava: "Gregório confessou!". Dois dias depois, em 8 de setembro, informava: "Gregório continua fazendo revelações" (O Globo, 6 e 8 setembro de 1954, p. 1).

Dez dias depois, a edição especial, que preparava a síntese do acontecimento sob o título "0 Livro Negro da Corrupção" (O Globo, 26 de setembro de 1954. Edição Extra), estampava a confirmação dos nomes dos mandantes do crime, incluindo políticos, como Euvaldo Lodi, militares como o General Mendes de Morais, e o irmão do Presidente, Benjamin Vargas (O Globo, 18 de setembro de 1954).

A mesma edição publica a fac-símile das contas de Gregório, "referentes ao mês de junho, do armazém que fornecia gêneros à sua família, na importância de Cr\$10.250,00". E concluía: "Essa conta, como se vê, quantia elevada, foi paga, como as outras com dinheiro da Nação!" (O Globo, 18 de setembro de 1954, p. 1).

A identificação da corrupção nas cercanias de poder fornecia 0 aval para as ações e para a campanha desenvolvida contra o ex-presidente. Combater a corrupção se constituía numa tradição argumentativa do periódico, que, assim, perpetuava crenças, comportamentos e repetia gestos singulares, inscrevendo-os num longo período, de tal forma que as palavras de ordens do passado soam como se fossem imemoriais.

A tradição é, portanto, construída a partir da continuidade de conteúdos, sem referência à mensagem original. Mas a mensagem original, a rigor, estava presente em agosto de 1954. Hoje, passados mais de 60 anos daquele acontecimento, não é possível - se não escavarmos o passado - identificar a origem dos argumentos duradouros do periódico. Há, portanto, um esquecimento, como encobrimento do acontecimento origem, 0 que torna ainda mais difícil a identificação da memória declaratória do jornal em momentos de crise política, quando argumentos similares são acionados.

\section{Considerações Finais}

Procuramos mostrar como, através de artifícios narrativos, pode-se acionar mecanismos fundamentais para a construção do que estamos denominando memória declaratória dos meios de comunicação, na qual acontecimentos produzidos no passado são reatualizados no presente em situações análogas, utilizando-se os mesmos argumentos, atores políticos similares e fatos construídos na esteira das mesmas tramas acontecimentais. Usando diversas dimensões do esquecimento e, sobretudo, o jogo entre lembrança e esquecimento produz-se uma narrativa com a pretensão de ser comum ao público criando 
a sensação da existência de uma memória dita coletiva. 0 objetivo último é sedimentar uma posição política e uma escolha a partir de um discurso apresentado como sendo comum a todos.

Nesse processo há que deixar à mostra os gestos das testemunhas, que legitimam as ações na esfera política. Assim, a opinião do jornal, no caso aqui estudado, de $O$ Globo, é sempre referendada pelas declarações de outrem ou por "documentos" que comprovariam a verdade dos testemunhos. Ao revelarem essas falas e os documentos, apresentados sempre como factuais, os periódicos se constituem em testemunhas de uma era, legitimando sua ação na esfera política.

A memória pode ser compreendida, assim, como remarca Henri Rousso (2016, p. 20), como um "conjunto de discursos, de reivindicações, de práticas, de políticas, de realizações que tem por objetivo representar o passado histórico em geral e certos episódios históricos em particular"2. Pode-se, portanto, falar de uma espécie de "memorialização", ou seja, de uma "mise en mémoire" ${ }^{3}$ que na visão do historiador constrói-se na dependência dos regimes de historicidade (HARTOG, 2014) característicos de cada época.
Mesmo diante dessa constatação - que permite dizer que o passado, o presente e 0 futuro são perceptíveis de maneira diferenciada em função dos regimes de historicidade existentes em momentos históricos diversos - pode-se pensar numa permanência de mecanismos memoráveis que são acionados a partir de narrativas construídas de maneira semelhante quando são oferecidas situações análogas.

A narrativa testemunhal do jornalismo é, assim, construída como atemporal, possuindo uma história própria, que, ao mesmo tempo, fixa 0 passado e torna possível revisitá-lo no futuro como passado imóvel. Ao se isolar na fixação textual sob a forma de documento, reafirma seu papel de imobilizador do tempo e deixa antever os recursos memoráveis que são acionados ao sabor do desejo do desfecho da trama, mas também em função do caráter de testemunha que assumem perante 0 público.

\section{Analisar esses movimentos é revelar o tipo de} memória declaratória que produzem, e distinguir os mecanismos de acionamento da memória, incluindo as múltiplas dimensões do esquecimento. Afinal, como remarca Rousso (2016), a memória social é antes de tudo um fato de comunicação. outros, RICOEUR, 2007; HUYSSEN, 2000; ROUSS0, 2016, LE GOFF, 1997; NORA, 1984. Sobre a relação memória e meios de comunicação cf. entre outros, BARBOSA, 1993, 2002, 2007, 2008, 2012, 2016; e RIBEIRO, 2003; RIBEIR0 e FERREIRA, 2007; BARBOSA e RIBEIRO, 2009; RIBEIR0, 2013, entre outros. 
Assim, os jornais, nos casos aqui analisados, transmitem suas representações memoráveis, ao mesmo tempo em que as atualizam em outros contextos, produzindo argumentos análogos na memória declarativa da qual se valem periodicamente.

\section{Referências}

BARBOSA, Marialva. Senhores da Memória. Tese para concurso público professor titular. Niterói: Universidade Federal Fluminense, 1993.

. "Medios de comunicacion y

conmemoraciones". Estrategias de reactualizacion y construccion de la memoria". Signo y Pensamiento, v. XX, p. 104-112, 2002.

"Meios de comunicação e usos do pasado": In: RIBEIRO, Ana Paula Goulart e HERSCHMANN, Micael. Comunicação e História. Interfaces e novas abordagens. Rio de Janeiro: MauadX, 2008.

. "Midias e usos do passado: o esquecimento e o futuro". Galáxia (PUCSP)., v.12, p.13 - 26, 2007.

"O passado que nos afeta e nos consome:

o esquecimento como ação memorável dos meios de comunicação" In: (org). Entretenimento, felicidade e memória: forças moventes do contemporâneo.1 ed. São Paulo : Anadarco, 2012, v.1, p. 173-192.

. "Meios de Comunicação: Lugar de

Memória ou na história?". Revista Contracampo, v. 34, n. 3, dez/2015-mar/2016.

GRAMSCI, A. Maquiavel, a política e o Estado moderno. Rio de Janeiro: Civilização Brasileira, 1978.

HUYSSEN, Andreas. Seduzidos pela memória. Rio de Janeiro: Artiplano, 2000.

HARTOG, François. Regimes de historicidade: presentismo e experiências do tempo. Belo Horizonte: Autêntica, 2014.
LE GOFF, Jacques. Memória. Enciclopédia Enaudi.

Lisboa: Casa da Moeda, 1997.

NORA, Pierre. Les Lieux de Mémoire. La République. Présentation. Entre mémoire et histoire. Paris: Gallimard, 1984.

RIBEIR0, Ana Paula Goulart . "Memória de Jornalista: um estudo sobre o conceito de objetividade nos relatos dos homens de imprensa dos anos 1950". In: Estudos de Comunicação. Livro do XI Encontro Anual da Compós. Porto Alegre: Ed. Sulina, 2003.

RIBEIR0, Ana Paula Goulart e BARBOSA, Marialva. "Memória, relatos autobiográficos e identidade institucional”. Comunicação e Sociedade, v. 28, n. 47, 2007.

RIBEIR0, Ana Paula Goulart, FERREIRA, Lucia Maria Alves (Org.). Mídia e Memória - A produção de sentidos nos meios de comunicação. Rio de Janeiro: Mauad X, 2007.

RIBEIR0, Ana Paula Goulart. "A memória e o mundo contemporâneo". In: RIBEIR0, Ana Paula Goulart; FREIRE FILHO, João; HERSCHMANN, Micael. (Org.). Entretenimento, Felicidade e Memória: forças moventes do contemporâneo. São Paulo: Anadarco, 2013.

RICOEUR, Paul. A memória, a história, o esquecimento. Campinas: Editora Unicamp, 2007.

ROUSSO, Henry. Face ao passé. Essais sur la mémoire contemporaine. Paris: Belin, 2016.

TODOROV, T. Les abus de la mémoire. Paris: Arléa, 1995. 


\begin{tabular}{|c|c|}
\hline $\begin{array}{l}\text { Media manipulation } \\
\text { or memory declaration } \\
\text { dimension? }\end{array}$ & $\begin{array}{l}\text { Manipulación mediática } \\
\text { o la dimensión declaratoria } \\
\text { de la memoria? }\end{array}$ \\
\hline $\begin{array}{l}\text { Abstract } \\
\text { From a historical example of twentieth-century politics } \\
\text { - the crisis of the Second Vargas Government - the } \\
\text { purpose of the text is to show how in the memorable } \\
\text { dimension the media make use of discursive } \\
\text { articulations around the same event, producing a } \\
\text { narrative in which the forgetting takes center stage. It } \\
\text { stands out in the analysis of the period that precedes } \\
\text { the (almost) end of the crisis of } 1954 \text { - culminating } \\
\text { with Vargas' suicide - the deep dimension of a } \\
\text { journalistic memory that is constantly being updated. } \\
\text { Keywords } \\
\text { Memory. Media. Vargas Government }\end{array}$ & $\begin{array}{l}\text { Resumen } \\
\text { A partir de un ejemplo histórico de la política del } \\
\text { siglo XX -la crisis del Segundo Gobierno Vargas- el } \\
\text { objetivo del texto es mostrar cómo en la dimensión } \\
\text { memorable los medios de comunicación hacen uso } \\
\text { de articulaciones discursivas en torno a un mismo } \\
\text { acontecimiento, produciendo una narrativa en la que } \\
\text { el olvido asume un papel central. Se destaca en el } \\
\text { análisis del período que precede al (casi) desenlace } \\
\text { de la crisis de } 1954 \text {-que culmina con el suicidio } \\
\text { de Vargas- la dimensión profunda de una memoria } \\
\text { periodística que se actualiza sin cesar. } \\
\text { Palabras clave } \\
\text { Memoria. Médios de comunicación. Gobierno Vargas }\end{array}$ \\
\hline
\end{tabular}




\section{Expediente}

A revista E-Compós é a publicação científica em formato eletrônico da Associação Nacional dos Programas de Pós-Graduação em Comunicação (Compós). Lançada em 2004, tem como principal finalidade difundir a produção acadêmica de pesquisadores da área de Comunicação, inseridos em instituições do Brasil e do exterior.

\section{E-COMPÓS I www.e-compos.org.br I E-ISSN 1808-2599}

Revista da Associação Nacional dos Programas de Pós-Graduação em Comunicação. Brasília, v.20, n.2, maio/ago. 2017. A identificação das edições, a partir de 2008, passa a ser volume anual com três números. Indexada por Latindex I www.latindex.unam.mx

\section{CONSELHO EDITORIAL}

Alda Cristina Silva da Costa, Universidade Federal do Pará, Brasil Alfredo Luiz Paes de Oliveira Suppia, Universidade Estadual de Campinas, Brasil Álvaro Larangeira, Universidade Tuiuti do Paraná, Brasil Ana Carolina D. Escosteguy, Pontifícia Universidade Católica do Rio Grande do Sul, Brasil Ana Regina Barros Rego Leal, Universidade Federal do Piauí, Brasil Ana Carolina Rocha Pessôa Temer, Universidade Federal de Goiás, Brasil Andrea França, Pontifícia Universidade Católica do Rio de Janeiro, Brasil André Luiz Martins Lemos, Universidade Federal da Bahia, Brasil Angela Cristina Salgueiro Marques, Faculdade Cásper Líbero, Brasil Ângela Freire Prysthon, Universidade Federal de Pernambuco, Brasil Antonio Carlos Hohlfeldt, Pontifícia Universidade Católica do Rio Grande do Sul, Brasil Arthur Ituassu, Pontifícia Universidade Católica do Rio de Janeiro, Brasil Bruno Campanella, Universidade Federal Fluminense, Brasil Cláudio Novaes Pinto Coelho, Faculdade Cásper Líbero, Brasil Carlos Eduardo Franciscato, Universidade Federal de Sergipe, Brasil Denise Tavares da Silva, Universidade Federal Fluminense, Brasil Eduardo Vicente, Universidade de São Paulo, Brasil Eliza Bachega Casadei, Escola Superior de Propaganda e Marketing - SP, Brasil Elizabeth Nicolau Saad Corrêa, Universidade de São Paulo, Brasil Erick Felinto de Oliveira, Universidade do Estado do Rio de Janeiro, Brasil Erly Vieira Júnior, Universidade Federal do Espírito Santo, Brasil Francisco de Assis, FIAM-FAAM Centro Universitário, Brasil Francisco Elinaldo Teixeira, Universidade Estadual de Campinas, Brasil Frederico de Mello Brandão Tavares, Universidade Federal de Ouro Preto, Brasil Gabriela Reinaldo, Universidade Federal do Ceará, Brasil

Gilson Vieira Monteiro, Universidade Federal do Amazonas, Brasil Gustavo Daudt Fischer, Universidade do Vale do Rio dos Sinos, Brasi Itania Maria Mota Gomes, Universidade Federal da Bahia, Brasil Jiani Adriana Bonin, Universidade do Vale do Rio dos Sinos, Brasil José Afonso da Silva Junior, Universidade Federal de Pernambuco, Brasil José Luiz Aidar Prado, Pontifícia Universidade Católica de São Paulo, Brasi
Juçara Gorski Brittes, Universidade Federal de Ouro Preto, Brasil Juliana Freire Gutmann, Universidade Federal da Bahia, Brasil Laura Loguercio Cánepa, Universidade Anhembi Morumbi, Brasil Letícia Cantarela Matheus, Universidade do Estado do Rio de Janeiro, Brasil Liziane Soares Guazina, Universidade de Brasília, Brasil Luíza Mônica Assis da Silva, Universidade Católica de Brasília, Brasil Maria Ataide Malcher, Universidade Federal do Pará, Brasil Maria Elisabete Antonioli, Escola Superior de Propaganda e Marketing - SP, Brasil Maria das Graças Pinto Coelho, Universidade Federal do Rio Grande do Norte, Brasil Marcel Vieira Barreto Silva, Universidade Federal da Paraiba, Brasil Marcia Tondato, Escola Superior de Propaganda e Marketing, Brasil Marli Santos, Universidade Metodista de São Paulo, Brasil Márcio Souza Gonçalves, Universidade do Estado do Rio de Janeiro, Brasil Mauricio Mario Monteiro, Universidade Anhembi Morumbi, Brasil Mauricio Ribeiro da Silva, Universidade Paulista, Brasil Mauro de Souza Ventura, Universidade Estadual Paulista, Brasil Mayka Castellano, Universidade Federal Fluminense, Brasi Micael Maiolino Herschmann, Universidade Federal do Rio de Janeiro, Brasil Mozahir Salomão Bruck, Pontifícia Universidade Católica de Minas Gerais, Brasil Nísia Martins Rosario, Universidade Federal do Rio Grande do Sul, Brasil Potiguara Mendes Silveira Jr, Universidade Federal de Juiz de Fora, Brasil Rafael Grohmann, FIAM-FAAM - Centro Universitário, Brasil Raquel Ritter Longhi, Universidade Federal de Santa Catarina, Brasil Regiane Regina Ribeiro, Universidade Federal do Paraná, Brasil Roberto Elísio dos Santos, Universidade Municipal de São Caetano do Sul, Brasil Rodolfo Rorato Londero, Universidade Estadual de Londrina, Brasil Sérgio Luiz Gadini, Universidade Estadual de Ponta Grossa, Brasil Simone Maria Andrade Pereira de Sá, Universidade Federal Fluminense, Brasil Simone Maria Rocha, Universidade Federal de Minas Gerais, Brasil Suzana Reck Miranda, Universidade Federal de São Carlos, Brasil Tarcyanie Cajueiro Santos, Universidade de Sorocaba, Brasil Tatiana Oliveira Siciliano, Pontifícia Universidade Católica do Rio de Janeiro, Brasil Veneza Mayora Ronsini, Universidade Federal de Santa Maria, Brasil

\section{CONSELHO CIENTÍFICO}

Cristiane Freitas Gutfreind, Pontifícia Universidade Católica do Rio Grande do Sul, Brasil | Eduardo Antônio de Jesus, Universidade Federal de Minhas Gerais, Brasil | Eduardo Morettin, Universidade de São Paulo, Brasil I Irene de Araújo Machado, Universidade de São Paulo, Brasil I Miriam de Souza Rossini, Universidade Federal do Rio Grande do Sul, Brasil

\section{COMISSÃO EDITORIAL}

Eduardo Antonio de Jesus, Universidade Federal de Minas Gerais, Brasil I Igor Pinto Sacramento, Universidade Federal do Rio de Janeiro, Brasil I Kelly Cristina de Souza Prudencio, Universidade Federal do Paraná, Brasil I Osmar Gonçalves dos Reis Filho, Universidade Federal do Ceará, Brasil

\section{CONSULTORES AD HOC}

Cesar Augusto Baio Santos, Universidade Federal do Ceará, Brasil I Lilian França Universidade Federal de Sergipe, Brasil I Maria Aparecida Baccega, Escola Superior de Propaganda e Marketing, Brasil I Márcia Benetti, Universidade Federal do Rio Grande do Sul, Brasil I Miguel Serpa Pereira, Pontifícia Universidade Católica do Rio de Janeiro, Brasil | Renato Essenfelder, Escola Superior de Propaganda e Marketing, Brasil

\section{EQUIPE TÉCNICA}

ASSISTENTE EDITORIAL Márcio Zanetti Negrini | REVISÃO DE TEXTOS Melina Santos | EDITORAÇÃO ELETRÔNICA Roka Estúdio I IMAGEM DE CAPA Silas de Paula

COMPÓS I www.compos.org.br

Associação Nacional dos Programas de Pós-Graduação em Comunicação

Presidente

Marco Roxo

Programa de Pós-Graduação em Comunicação - UFF marcos-roxo@uol.com.br

Vice-Presidente Isaltina Gomes Programa de Pós-Graduação em Comunicação - UFPE isaltina@gmail.com

Secretária-Geral

Gisela Castro

Programa de Pós-Graduação em Comunicação e Práticas de Consumo - ESPM castro.gisela@gmail.com

CONTATO I revistaecompos@gmail.com 